\title{
Teaching Resource for the Teaching of Geometry: Circular Trigonometric Geoplane
}

\author{
Derling José Mendoza Velazco ${ }^{1 *}$, Yoandry Rivero Padrón ${ }^{1}$ \\ ${ }^{1}$ Universidad Tecnológica Israel, ECUADOR \\ *CORRESPONDENCE: $\square$ derling969@gmail.com
}

\begin{abstract}
The difficulty in the process of trigonometry teaching, served as a stimulus for the present research, in which the objective consisted of designing and proposing the use of a Trigonometric Cicular Geoplane for the construction of meaningful learning in the area of Mathematics at Israel Technological University. For Its development, a field research, descriptive type, and a special project modality was conducted. As key informants, the participation of twenty (20) students and three (3) teachers that work in distinct levels of the institution described above. In order to gather information, observations and interviews were used, and the instrument of an observation and interview guides were submitted to a valid process. For the purpose of reliability, it was implemented through a standardization of registers and categories, then the findings were analyzed based on a cultivated and descriptive analysis in order to elaborate the conclusions in search of the proposed objectives about the design and use of the teaching tool that contributes in a positive manner to the teaching and learning of Geometry, in the same manner, the motivation and receptivity to use of Geoplane were used, in response to permit the development of innovated methodologies that show a change of andragogy practice, as it is, to teach learning skills that last a lifetime.
\end{abstract}

Keywords: mathematic education, meaningful learning, trigonometry

\section{INTRODUCTION}

The learning and teaching process of mathematics in higher education, has converted, during the last few years, in a highly complex and fundamental task. To that effect, teachers of mathematics and other areas of scientific knowledge find with frequency in front of demanding teachers, changers, and innovators in which require major attention on the part of people that are dedicated to the research in the field of mathematics education and, above all, to the development of learning units for the treatment of the variety of themes in and out of this field.

In this context, those who are connected to the teaching of mathematics consider that the students should acquire diverse forms of mathematics in and for different situations, as much for their posterior application as well as strengthening learning strategies in the process of teaching and learning. This demands, obviously, to deepen the corresponding methods of learning and, very particularly, about techniques and resources to be applied in the educative context.

Article History: Received 2 July $2018 \bullet$ Revised 1 October $2018 \bullet$ Accepted 22 October 2018

(C) 2019 by the authors; licensee Modestum Ltd., UK. Open Access terms of the Creative Commons Attribution 4.0 International License (http://creativecommons.org/licenses/by/4.0/) apply. The license permits unrestricted use, distribution, and reproduction in any medium, on the condition that users give exact credit to the original author(s) and the source, provide a link to the Creative Commons license, and indicate if they made any changes. 


\section{THEORETICAL BASIS}

\section{Mathematic Education}

Numerical Sciences have always existed in humanity since man made use of his reason, in which it showed that society considers of great importance the scientific formation of being, since its infant context until the development of its intellectual maturity. The mathematics are essential in all human lives, for this reason, it is contemplated inside education, as one of the areas that require attention. In this sense, Mora (2005), indicates that the teaching and learning process of mathematics considerably contributes with the permanent culture of mathematics, its conceptual advance and the conformation of groups and subjects motivated and convinced of the importance, utility, potential, and power that characterize to mathematics when they are focused from one culture of learning and teaching multipurpose and interdisciplinary, extremely additional contrary to the actual predominant tendencies.

The product of the scientific knowledge in mathematics is fundamental, not only for the student, but also for each person. It is, also, a basic human right to have access to scientific knowledge, understand it and to make use of it. Mathematic as science has structured a reality that embarks different areas, such as geometry, history, art, among others. The cultural diversity of the permitted cognitive enrichment of this science allows to understand different perspectives of the research (Kouvela, Hernandez, \& Croft, 2018).

\section{Motivation in Learning}

According to Chiavenato (2006), motivation is the interest that the student has for his or here's own learning or for activities that drive the student. Today it is a key factor in learning, due to this, it is important to understand why in adolescents, motivation descends and with it mathematic performance, especially passing through secondary to higher education.

The interest can be acquired, to maintain or increase in function of intrinsic and extrinsic elements. One must distinguish from what has traditionally been called in institutions as motivation that is nothing more than what the professor does in order to motivate students (Turner, Bogner, \& Christensen, 2011). The term, motivation, alludes to the aspect in virtue in which the living subject is an auto-dynamic reality that differentiates from inert beings. A living organism distinguishes itself from those that are not because it can motivate themselves. Motivation, relates, at least to these determinants that make the subject behave in a determined manner having in themselves the principle of its own movement.

According to Vigotsky (1978), the superior psychological processes of development, in the human being, is a complex activity that includes the use of language, thought, memory, attention, perception and abstraction. Learning is a psychological process of superior order that occurs by internalization of external activities above the base of internal structures. It is helped by material ordered instruments, called resources, and of the psychological order called signs.

In the learning process, cognitive structures are reconstructed and consist in transforming activities that occur externally in activities that occur internally, it is to say, things happen from an interpersonal plain to and intrapersonal plain. The external sign converts internally with meaning and is used, among other things, to remember, think, analyze, and speak.

A procedure implies the task as a practiced activity and external, and the though process, as a cognitive and internal activity. In mathematics, the learning procedure is based on the idea of progressive construction and advancement detects through the execution of the steps that compose, the correction of the said execution, the capacity of knowing when and how to use it. A procedure is learned by practicing, applying, reflecting, and analyzing. The learning is based on the progressive transfer of the control and of the responsibility in the execution (Yeon, 2018).

Achievement through motivation consists of a network of cognitive and affective connections that related with the personal development and impulse of people to demand more, persevere more, and use capabilities effectively, acquired abilities and knowledge. Therefore, when goals, tasks, beliefs, and activities enabling achievement have been established, action or performance of the student is a conscience act with intentionality. For this supposes that the effect of motivation in achievement reflect in the elaboration of such tasks that represent cognitive conflicts generated by new knowledge. 


\section{Motivation in the Educational Process of Mathematics}

For Meyer (2007), when a mathematics teacher prepares an activity, the principal concerns reside in how to maintain students' interests in the theme that is being developed. More so, we ask how we should structure our teaching instruction to attract and maintain the attention of the students. After all, the mathematics professor has, in general, the stigma of being the professor a difficult and boring material.

The creation of teaching materials such as filmstrip posters, flipchart, and more, were in the past an activity of the professors to achieve this mission (Sinclair, 2018). Still today it continues to be a valuable resource. On the other side, the ease in which it can access information via internet, the introduction of multimedia platforms in education and the development of interactive and educative software plants a new paradigm in which, the mathematics professor can develop educative strategies that motivate mathematic learning.

In this sense, according to Arrieche (2008), games are seen as only entertainment or fun, as something useful to motivate, but nothing more. Actually, as a result of research in different aspects of teaching and learning of Mathematics, the teacher is much more conscience of the educational potential of teaching games or instruments.

Another part is the work of the teacher in searching for strategies that motivate the student to study Mathematics. There are several forces that have been plated throughout time, but the best plant the possibility to motivate students is the creation of teaching tools that permit to facilitate the process of teaching and learning of Mathematics in universities, high schools or institutions. This type of strategy, not only allows to present to the student Mathematic themes that are interesting, but also to be outside of the formal curriculum of the course, liberates the student of concern of having to learn it, it also presents as an entertainment and an activity of fun character.

Unfortunately, the practice of teaching instruments at the university level has fallen in disuse, owed in part to the Mathematic culture of professors, whom maintain an academic methodology in its educative praxis, as a consequence, from the program of activities that result little interest to the students and in part to the excess of work that is submitted the teachers in institutional functions as research (Hammoudi, 2018). Nonetheless, it is necessary to produce forces to rescue this component of teaching Mathematics, which, is an important strategy in the process of teaching and learning.

\section{Trigonometry}

Trigonometry is defined by Becerra (2018), as the area that studies relationships between sides and angles of triangles. Its etymology provides triangle and metric measurements. In the same form, in the dictionary etymology from the language Castellana, Corominas (1987), establishes that trigonometry, 1727. Ch.. Del gr metron me métron 'measurment with trigonos 'triangle (at their time ch. three 'three and 'angle) Therefore, trigonometry is a part of Mathematics that generically studies the relationship between angles, its measurements and sides of the triangle, in other words geometric figures of measurements with three angles.

In Mathematics education and especially in the area of trigonometry, it is utilized in great quantity of occasions, masterful classes through expositive methods, considering that there exists a great effectiveness in the transmission of knowledge, on the contrary to the power to understand the essential in enlightened themes in the classes. These aspects, create in the student population increase emptiness in which a theme or areas of numerical sciences.

Geometry, as one of the most demonstrative mathematic discipline, concrete and intuitive, is found interrelated to the human being universe, now that they can demonstrate different forms, theorems and axioms, by instruments or feasible instruments. In which the instruments, these can be designed in an optimum and adequate manner to experiment geometric concepts, facilitating the possibility of recreating figures and imagines with geometric patrons of phenomenological nature.

\section{Geoplane}

Espinoza (2015), expresses that the first geoplane presented in the first publication together with International Commission to improve the teaching of Mathematics in 1961. The original Geoplane was designed by Gattegno (1911-1988) consisted in a board of wood with pivots and nails formed in an orthometric frame. As a teaching instrument, it presented to calculus areas and parameters, uniting nails with ligaments or chords, demonstrating the construction of geometric figures. 
According to Potoy (2007), geoplane is a teaching resource for the introduction of a grand part of geometric concepts; manipulative character. As a teaching resource induces the topics of geometry, facilitates the manipulative aspect to the teacher to generate opening of the imagination and feasibility in the classes, where abstract contents of mathematics can dissolve through the use and creativity of students.

There actually exist different types of geoplane, between them are the ortometric, which consists of one table, where the keys are placed, and formulating squares. The isometric geoplane, used for the calculation of trigonometric triangles, and the circular geoplane where keys are located in a circular manner, placing an equal distance from the center to their extremes. The dimensions of geoplanes depend on the necessity of its designer.

\section{Theory of Meaningful Learning}

Meaningful learning is understood as the dimension of knowledge that the student has. Ausubel (1980), proposed in the current cognitive psychological, in which has its foundation in the existence of a cognitive structure, where the individual organizes the knowledge.

This structure should be taken into account at the moment of diagnosing, planning, executing, and evaluating the educative action, a position that previous knowledge are the support in which the student can acquire and process new knowledge through the capacity of relating with concepts that possess in the cognitive structure.

Citing the same author, Ausubel (1980), considers this theory as a psychological theory from learning in the classroom. It is a psychological theory because it occupies the same processes that the individual places in a game to learn. However, since this perspective does not include relative themes as the same psychology no from a general point of view, no from a development of optics, without placing emphasis on what occurs in the classroom when students learn; in the nature of this learning; in the conditions that require it in order to be produced; in these results and, consequently, in its evaluation, Ausubel (1976). It is a learning theory because it is its finality.

The Theory of meaningful Learning addresses each and every one of the elements, factors, conditions and types that guarantee the acquisition, the assimilation and retention of the content that the school offers to the student, in the way that acquires significance to themselves.

The origin of the meaningful Learning Theory is in the interest that Ausubel has to know how to explain the conditions and proprieties of learning, that can relate to effective forms and efficient to provoke of a deliberate manner stable, cognitive changes, susceptible of endowing the individual and social meaning Ausubel (1976). Given that what one wants to discover is that the learning that is produced in school be meaningful, Ausubel understands that a theory of school learning be realistic and scientifically viable should occupy a complex and meaningful character that has verbal and symbolic learning. In this way, and with the objective of achieving this significance, should pay attention to all and each one of the elements and factors that affect and can be manipulated by the end.

The thing that defines Ausubel's theory is " meaningful learning", an etiquette that is very present in the dialogues of teachers, curriculum designers and researchers in education and that, nonetheless, are also very much unknown of its origin and its justification. Meaningful learning is the continual process in which relates to a new knowledge or information with the cognitive structure that is learned in a form not arbitrary and substantive or not literal. This interaction with the cognitive structure does not produce in everything, but with present relative aspects in the same, that receive the name of anchoring ideas Ausubel (1980). The presence of ideas, concepts or inclusive propositions, clear and available in the mind of learning is that supplies its significance to the new content in interaction with itself (Mendoza \& Mendoza, 2018).

\section{METHODOLOGY}

For the effect of the research is applied to the research field, according to the Universidad Pedagogica Experimental Libertador UPEL (2016), consists in the systematic analysis of realistic problems, with the purpose of describing, interpreting, understanding its nature and components, explaining its causes and effects, or predict its occurrence, making use of methods of any paradigms or focuses of known or developing investigations. 


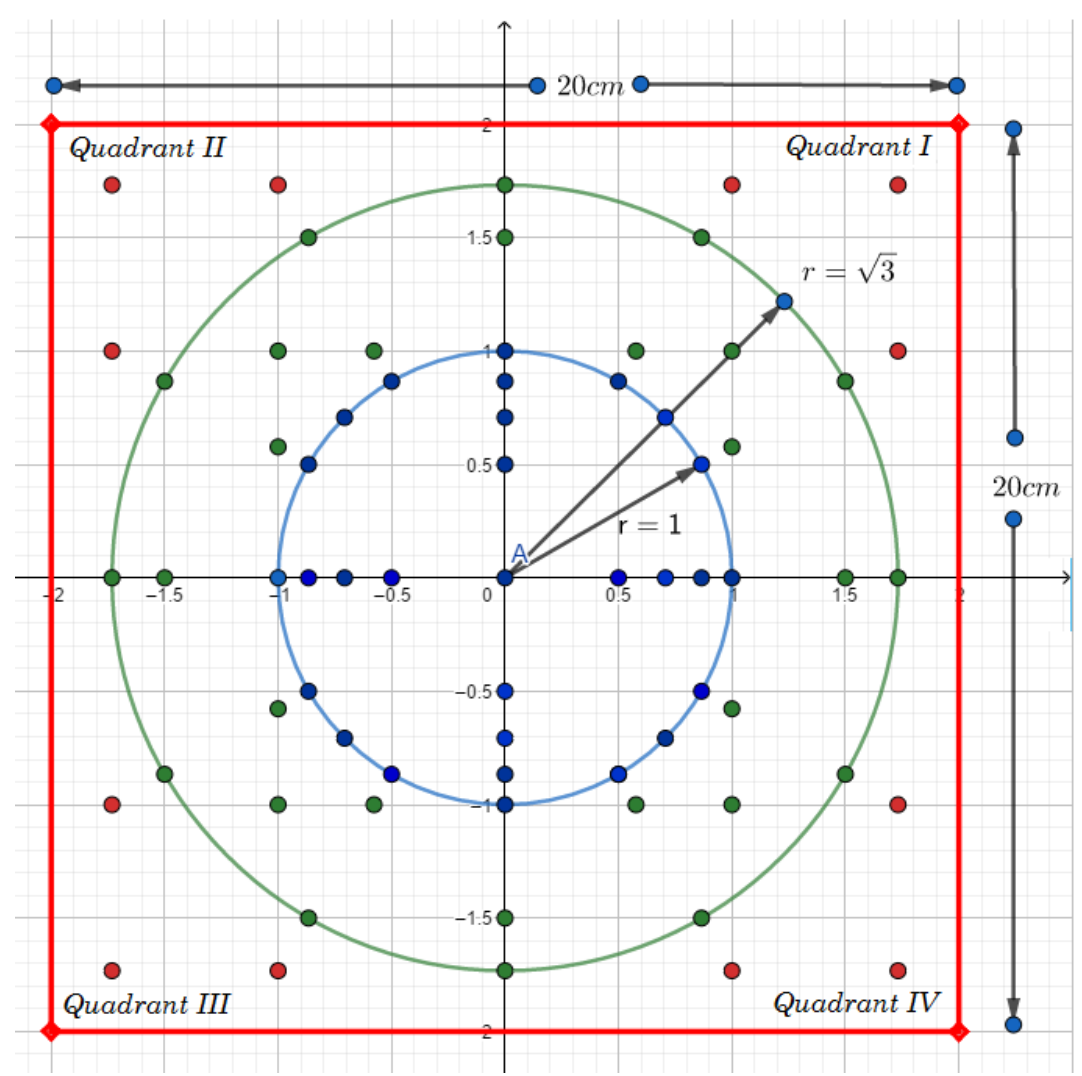

Figure 1. Trigonometric Circular Geoplane

In other words, its unquestionable value resides through them, the investigator can certify of the real conditions that the data have obtained, making it possible for revision or modification in the case of any issues arising.

At the same manner, a descriptive investigation was used, that for Hernandez, Fernandez and Baptista (2014) looked for specific proprieties, characteristics and personal profiles, groups, communities, processes, objects or whatever other phenomenon that was submitted to the analysis. It is to say, they expect to measure or collect information in an independent manner or joined above the concepts or variables that they refer to, that is, its objective is not to indicate how these are related.

For the other part, a modality of a special project was adopted, in which continuing from UPEL (2016), establishes that there are studies that bring tangible creations, susceptible of being used as solutions to demonstrated problems, or that respond to the needs and interests of a cultural type. These are included in the category of elaboration of works in textbooks and of educative support materials, software development, prototypes and of technological products in general, as well as those of literary and artistic creation.

It is to say, it is characterized as a special project, to be orientated to resolve a planted problem, through the search of a solution of difficulties and satisfaction of the needs of an institution, whose purpose it is to design a teaching material of the educative support in the teaching of Mathematics.

\section{RESULTS ANALYSIS}

After applying the diagnosis instruments proceeded to the construction of the trigonometric circular geoplane. The design of the trigonometric circular geoplane applied in the research, consists of a basic model of a rectangular table of $20 \mathrm{~cm}$ on four sides. Circumscribed in the subdivision of the Cartesian plane (4 quadrants) such as can be visualize in the Figure 1. Adjust a circumference of a radius of 1 of the color blue, more than a circumference of radius $\sqrt{ } 3$, both with a unique center from the point of origin.

In regards to the quantity and specific location of assigned points to the table, required of a total of 69 . Of those 29 points, are located in a concentrated circumference with a radius of 1 . Then 28 points in the green 


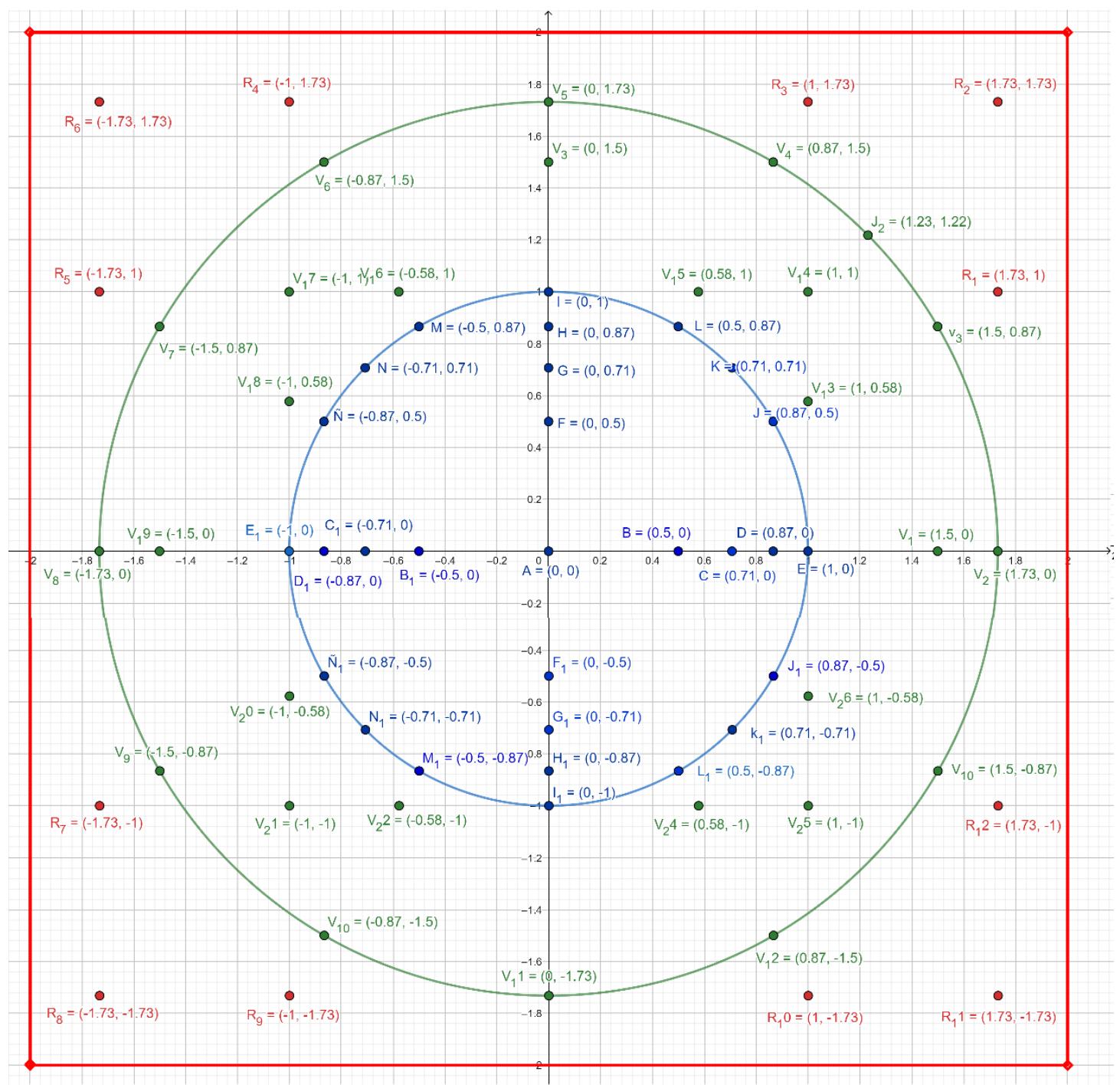

Figure 2. Location of the keys in the geoplane by means of Cartesian coordinates

line with a radius of circumference of $\sqrt{ }$, for the last 12 points of the color red is the external part. All of the points located in the following parts are described in the following Figure 2.

In the posterior part of the geoplane is located a basic formula of trigonometry (see Figure 3). 


\section{Trigonometry}

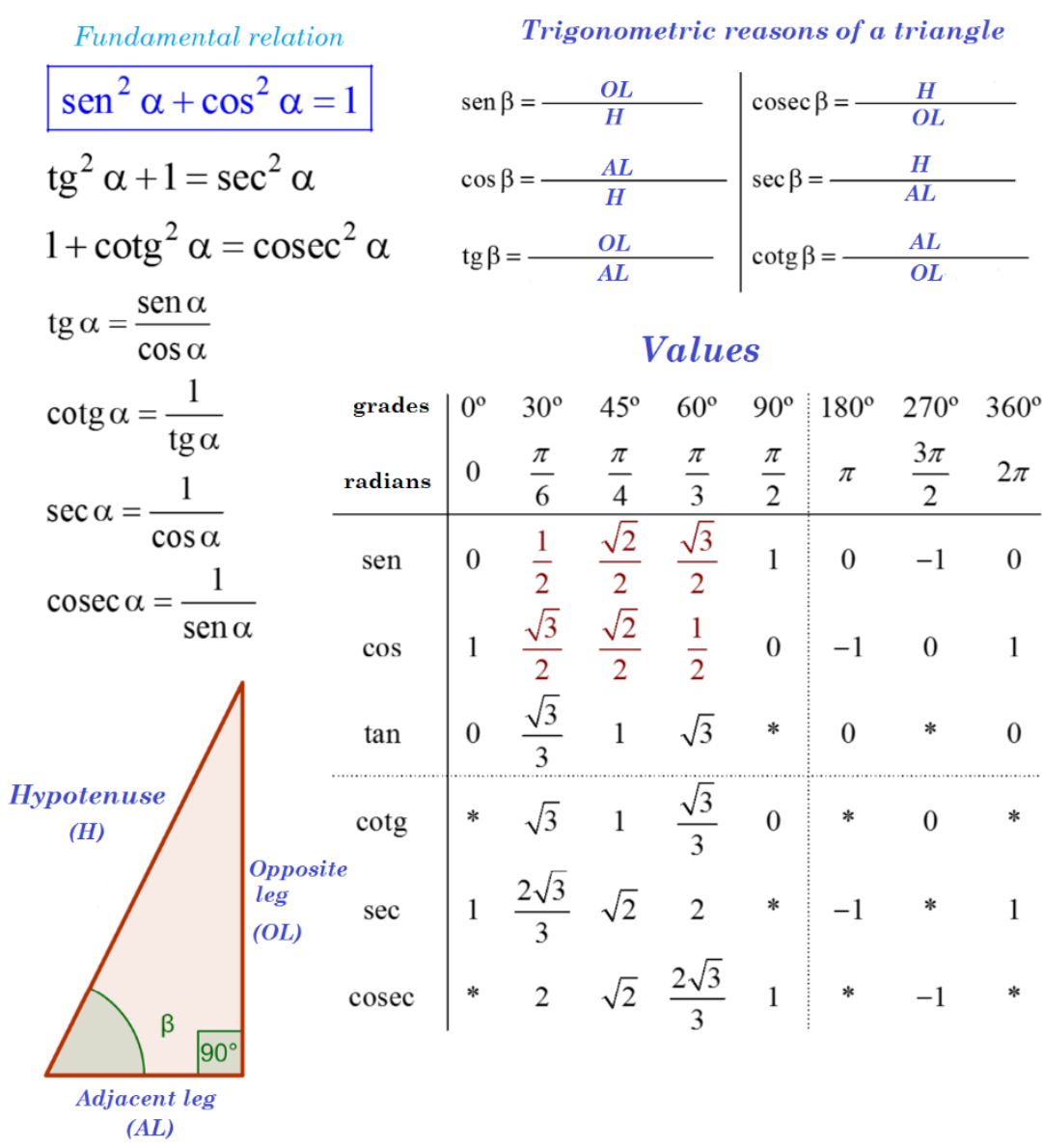

Figure 3. Trigonometry Formula

In the present framework, occupies the analysis and interpretation of the obtained information in the referred teaching methodology, through informants and observed events in the circumstances where mathematic activities untangle, whose purpose allows to examine the motivational characteristics of the students in the teaching of mathematic geometry under the incursion of the trigonometric circular geoplane. In order to construct theoretic elements that sustain the theoretic analysis of the results, a rigorous study of the data is required, immersed in a sequential analysis to develop previewed theme in the research.

Applying ligaments to the different colors in different points (or keys of the geoplane) can distinguish the formation of triangles, as a triangle of the violet ligament with vertices (D1, A, V)) with and inclination angle of $30^{\circ}$ with the horizontal axis, the blue ligament triangle, with vertices (R, A2, A), red triangle with vertices $(\mathrm{F} 2, \mathrm{D}, \mathrm{A})$, and finally the green triangle with vertices (D'1, L1, A). All are in the first quadrant of the Geoplane (see Figure 4). 


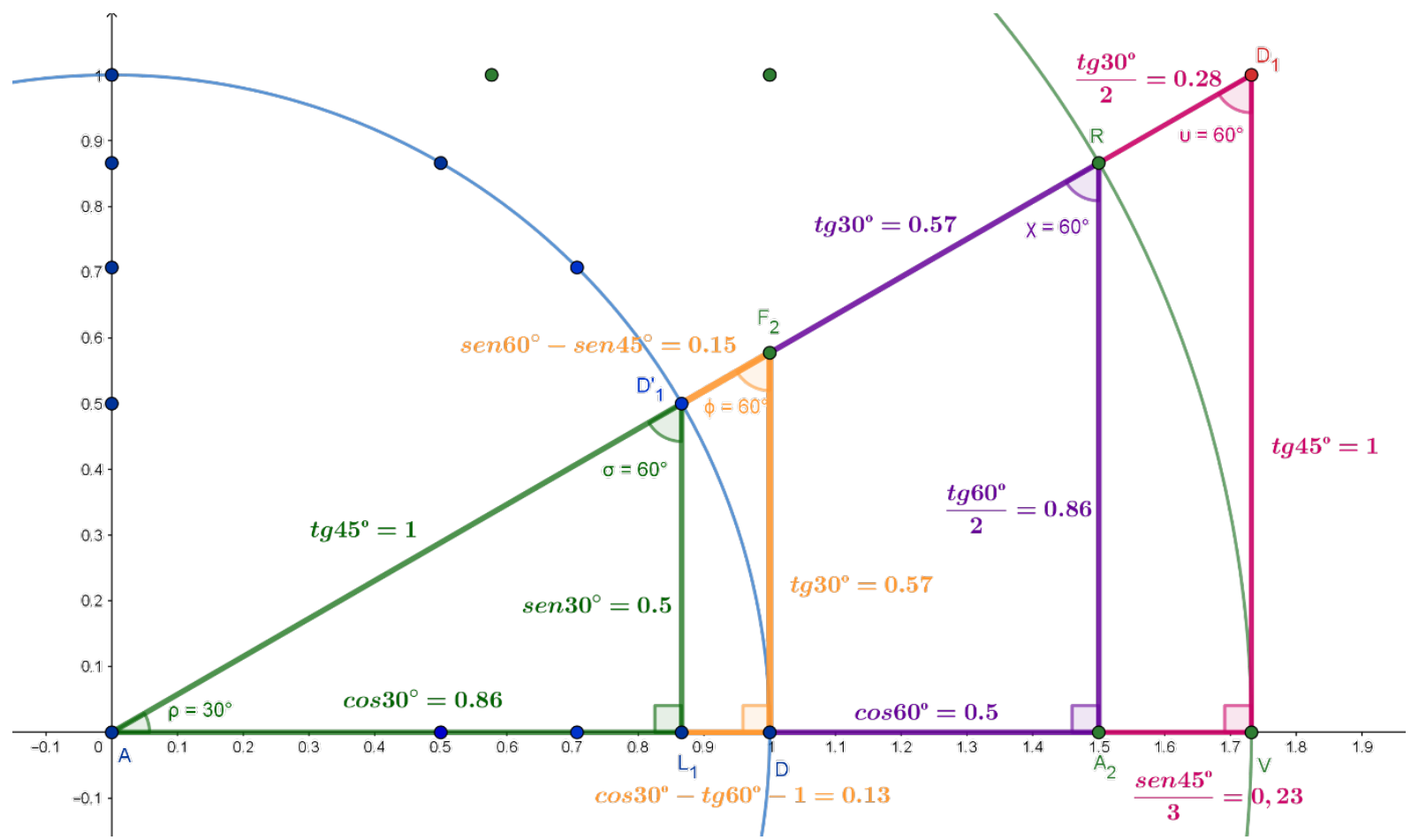

Figure 4. Formation of triangles in the first quadrant of the geoplane

From an analytical form, different theorems can be proven in the area of geometry, such as the Theales Theorem, in which the likeness of the triangles are found one on each side, establishing the likeness relationship between various triangles. For example, if we divide the segments F2R / DA2 = AD'1/aL1 = D'1 $\mathrm{F} 2 / \mathrm{L} 1 \mathrm{D}=\mathrm{R} \mathrm{D} 1 / \mathrm{A} 2 \mathrm{~V}$. It can also be shown the trigonometric proprieties, as $30^{\circ}$ in the triangle ADF2, where the longitude of the opposite side is from 0.58 equal to the sides of F2R with a longitude of 0.58 to complete the trigonometric sameness.

$$
\frac{F_{2} R}{D A_{2}}=\frac{D_{1} A}{A L_{1}}=\frac{D_{1} F_{2}}{D L_{1}}=\frac{R D_{1}}{V A_{2}}
$$

The geoplane application as a teaching instrument in the teaching of mathematics, contributes to two important aspects of education. The first in facilitating the logical and meaningful understanding of trigonometry and the second point is to facilitate the resolution of problems so that the students achieve in reaching the dominion of proprieties in the future and exposed trigonometric reasons in the development of each problem. At the same time, in the course of the research, the tool allowed creative execution and skill of studying the instant moment of confronting the problem, which were always conceived as unique themes and unreachable that were only found at the height of teachers, not the students, enforcing of this same manner in itself.

The use of the geoplane facilitates the triangle demonstration of trigonometric functions, in favor of less use of developed time in the classroom and the minimization of daily resource materials; such as an acrylic board and the construction or representation of images through slides, as can be visualized in Figure 5 . 


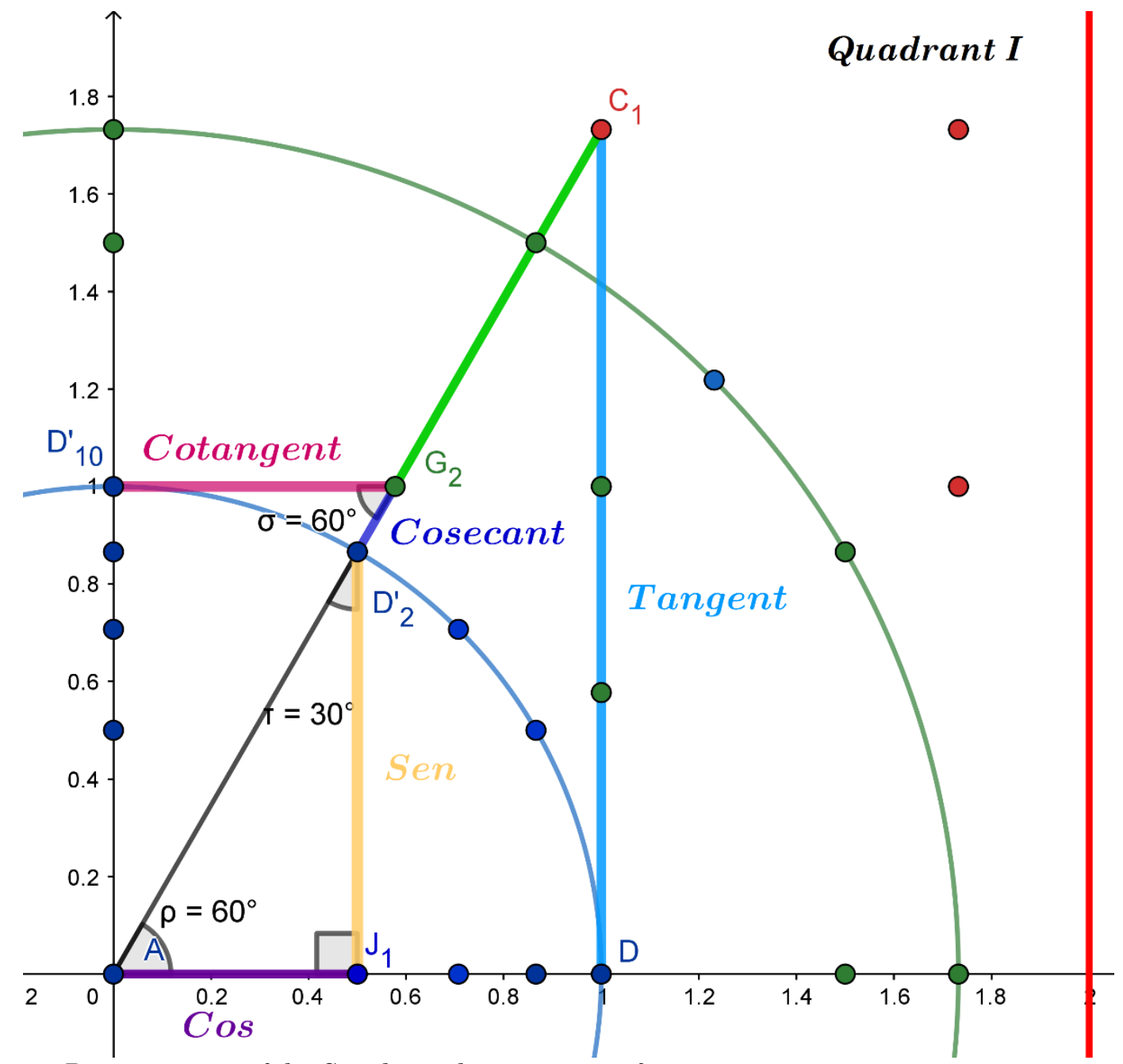

Figure 5. Representation of the Circular and trigonometric functions

It can be mentioned, in some importance of the use and applicability of mathematics in each instance for the human being, in particular, for university student who presents a deficit in the resolution of problems, in which, through the teaching explanation of geometry the students expressed feeling a little attracted to the material, in visualizing that they can obtain mathematic knowledge in a meaningful manner with a feasible instrument; applying the geoplane with the ends mean of motivating students and feeling the relationship between the enlightened theme and its usefulness in the studies, that have not been resolved, obtaining or calculating a simple digit, number or variable without sense or some interpretation.

Initially the shown activities of trigonometry displayed the disinterest of the students in the course, where the majority of students indicated that in the high school level were incomprehensible and that lead to bad memories. It is fitting to note that the majority of students did not remember the trigonometric reasons, the essence or meaning and application of the said functions, in part of a teaching tool, entails to eliminate the abstract vision of Mathematics in a simple and comprehensible world, without apathy or fear that teachers have planted since secondary education.

\section{CONCLUSIONS}

Designing and applying a teaching tool to generate a change in the teaching of Mathematics at the university level, was the initial point of the development of this research. Between the principal areas of Mathematics, geometry, represents being one of the most instinctive demonstrative, synthesized and united to the reality that is known. For this, the study enlightened numerous possibilities for realizing, through accessible and suitable materials, concepts, proprieties and demonstrations of trigonometry. 
Following, Giroux (1990), the teacher possesses the responsibility to discuss and analyze educative objectives and the ways of teaching, based on the social, political, and economic conditions particular to the institutional context; all are necessary to be able to be conscience of the existence of social relations and forms of knowledge that are impregnated in cultural and social values, that legitimize different lifestyles.

At the foundation, the author, a critical constructivist teacher, considers the student as a central subject of its learning which constructs and reinforces the knowledge, through reflection derived from its own compromise. From the artistic service of the teacher to the student is uniquely interpreted from the mathematic thought, with its creation of instant teaching and manipulation.

It is refined in the present study that the application of the circular geoplane as a teaching tool, performs and accomplishes with the possibilities of understanding and solving geometric problems, especially in trigonometry, also it is a great support for the university teacher that optimizes their andragogy work. The instrument allows students to be innovated producers of their own Mathematic conceptions, of a dynamic and imaginative form, as well as making it possible to construct a new meaningful meaning of the study of geometry.

At the same time, it was looked into that the students and teachers stop at one side of the academic or traditional system, developed only with the realization of postgraduate classes and continuous tasks, so that they integrated to the real situation and could form the study of geometry with a teaching character, creative and pleasant, where the student achieves to develop their creativity and reinforce their mental capacities. Therefore, it is observed in higher education to improve, that concrete teaching material was implemented in order to improve the quality of teaching and learning that left to the side of behaviorism.

Especially the students that hold their interest in other courses of their major, being shared with feasible and demonstrative teaching material in order to generate motivation, as well as a fun type or of applicable, at the same time, the students expressed their gratitude for the present model of the geoplane. Together it also enlightened the circumstance of knowing the Mathematic theme as a fun way, also is allowed to reinforce their knowledge through the activities in which allowed for development and being of such mathematic applications that are of great importance in the human being. Also, it is reiterated to be the first time that they have seen a course of this teaching form, for this reason, it was much appreciated by the students, recalculating that this way of teaching be applied in other courses.

\section{Recommendations}

After concluding the present research, it is recommended to demand to university professors of Mathematics to apply teaching material in their academic achievement, in particular the Trigonometric Circular Geoplane. Remembering the importance of self-study, demonstration, and conceptualization of trigonometric reasons.

Teaching to the student since basic education provides small justifications and demonstrations of themes for which, since its beginning, achieve to disperse the disinterest, fear or phobia that are presented to students in this field.

\section{Disclosure statement}

No potential conflict of interest was reported by the authors.

\section{Notes on contributors}

Derling José Mendoza Velazco - Israel Technological University, ECUADOR.

Yoandry Rivero Padrón - Israel Technological University, ECUADOR.

\section{REFERENCES}

Ausubel, (1980). Aprendizaje significativo. Barcelona: Círculo de Lectores, S.A.

Ausubel, D. P. (1976). Psicología educativa. Un punto de vista cognoscitivo. México: Trillas.

Becerra, J. (2018). Funciones trigonométricas. Universidad Nacional Autónoma de México.

Chiavenato, (2006). La motivación es el interés que tiene el alumno por su propio aprendizaje o por las actividades que le conducen a él. Colombia: Eduteka. 
Corominas, J. (1987). Diccionario etimológico de la lengua castellana. Madrid: Editorial Gredos.

Espinoza, N. (2015). Elaboración y uso adecuado del geoplano, origami y geogebra como material concreto y tecnológico para mejorar el logro de aprendizajes en el dominio de geometría en los estudiantes del segundo año sección "a" de la institución educativa "antonio ocampo"- curahuasi-abancay, 2013-2015. Universidad nacional de san agustín de arequipa facultad de ciencias de la educación.

Giroux, H. (1990). Los profesores como intelectuales. Hacia una pedagogía crítica del aprendizaje. Barcelona: Paidós.

Hammoudi, M. (2018). Predictive factors of students' motivation to succeed in introductory mathematics courses: evidence from higher education in the UAE. International Journal of Mathematical Education in Science and Technology. https://doi.org/10.1080/0020739X.2018.1529339

Hernández, R. Fernández, C, Baptista, P. (2014). Metodología De La Investigación. México: Mcgraw-HILL.

Kouvela, E., Hernandez, P., \& Croft, T. (2018). This is what you need to be learning": an analysis of messages received by first-year mathematics students during their transition to university. Mathematics Education Research Journal, 30(2), 165-183. https://doi.org/10.1007/s13394-017-0226-2

Mendoza, D. \& Mendoza, D. (2018). Information and Communication Technologies as a Didactic Tool for the Construction of Meaningful Learning in the Area of Mathematics. International Electronic Journal of Mathematics Education. 13(3), 261-271. https://doi.org/10.12973/iejme/3907

Meyer, R. (2007). Metodología de la Investigación. Bogotá - Colombia: Editorial Episteme.

Mora, D. (2005). Didáctica crítica, educación critica de las matemáticas y etnomatemáticas. Bolivia: Campo Iris.

Potoy, Y. Poveda, S. Alarcon, R. Gomez, P. Vilches Y. y Aleman, J. (2007). Material didáctico para la enseñanza - aprendizaje de conceptos de matemáticos. (el tangram y el geoplano). Universidad Nacional Autónoma de Nicaragua: Departamento de Matemática.

Sinclair, N. (2018). Review of Research for Educational Change: Transforming researchers' insights into improvement in mathematics teaching and learning. Mathematical Thinking and Learning, 20(2), 162166. https://doi.org/10.1080/10986065.2018.1443728

Turner, J., Bogner, K, \& Christensen, A. (2011). Motivating Mathematics Learning: Changes in Teachers' Practices and Beliefs During a Nine-Month Collaboration. American Educational Research Journal 48(3), 718 - 762. https://doi.org/10.3102/0002831210385103

UPEL, (2012). Manual de Trabajos de Grado y Maestría y Tesis Doctoral de la Universidad Pedagógica Experimental Libertador. Caracas, Venezuela: UPEL.

Vigotsky, (1978). Psicologia Y Pedagogia. Madrid: Editorial Océano.

Yeon, M. (2018). Further Investigation into the Quality of Teachers' Noticing Expertise: A Proposed Framework for Evaluating Teachers' Models of Students' Mathematical Thinking. EURASIA Journal of Mathematics, Science and Technology Education, 14(11), em1570. https://doi.org/10.29333/ejmste/92019 